\title{
ECS perseveration effect following varying amounts of training*
}

\author{
JOSEPH B. KEYES \\ Louisiana State University, Baton Rouge, Louisiana 70803
}

\begin{abstract}
Forty-eight naive female albino rats were trained to leverpress for sucrose, using a free operant procedure. The Ss were trained on a continuous reinforcement schedule (CRF) and were allowed to make 100, 300, or 500 leverpresses. Following acquisition, half of the Ss in each group received ECS. The remaining Ss were given no treatment. Results showed that ECS produced perseveration of the learned response for Ss allowed to make 100 leverpresses, but did not produce perseveration for the 300 - and 500-leverpress groups.
\end{abstract}

The effect of electroconvulsive shock (ECS) following a one-trial learning experience seems to be retrograde amnesia (RA) for that learning experience (Lewis, 1969). The most widely accepted explanation for this phenomenon has been a hypothesis of memory consolidation. This hypothesis suggests that following sensory input, a physiological consolidation process, operating over time, permanently fixes the memory trace. Presumably, then, the massive electrical interference produced by ECS interrupts the consolidation process and thereby prevents the permanent fixation of the memory trace (McGaugh, 1966).

Recently, however, studies have been conducted which do not support this position. Young and Galluscio (1970) trained two groups of rats to leverpress, using a discrete trial procedure. One group was trained on a continuous reinforcement schedule (CRF) and the other on a fixed ratio schedule (FR 3 ). Upon the completion of 1,000 acquisition trials, on treatment day, a leverpress produced footshock. For half the Ss in each group, footshock was followed by ECS; the other half received no ECS. All Ss were tested in an extinction session $24 \mathrm{~h}$ after treatment. The results indicated that, for both groups, ECS seemed to eliminate the suppression caused by the footshock.

More recently, Young and Day (1971) replicated the Young and Galluscio study, but used a variable ratio schedule (VR 2) in place of the FR schedule previously used. In this siudy, the results showed that ECS eliminated the footshock-produced suppression for CRF-trained Ss but not for Ss trained on a VR schedule.

In the Young and Day (1971) study, the amount of suppression produced by footshock was significantly less for VR-trained Ss than for CRF-trained Ss. However, in the Young and Galluscio (1970) experiment, there was no difference in the amount of footshock-produced suppression for FR- and CRF-trained Ss. This may

\footnotetext{
*This research was supported in part by a grant from the University Council on Research, Louisiana State University, to A. G. Young and by an NDEA Title IV predoctoral fellowship to the author.
}

account for the difference in the results between the two studies. Young and Day (1971) suggested that the effect of ECS may be an inflated rate of responding or a perseveration of responding in extinction. The authors further suggested that this would account for the fact that frequently partial reinforcement (PR) trained Ss given ECS do not show a significantly greater number of responses in extinction than do PR-trained Ss which do not receive ECS.

Keyes (1971), using a discrete trial procedure, found that after 1,000 leverpresses, CRF-trained Ss given ECS not preceded by footshock made significantly more responses in extinction than CRF-trained Ss given no treatment. However, FR-trained Ss given ECS did not respond significantly more in extinction than FR-trained Ss receiving no treatment. These results support the perseveration hypothesis suggested by Young and Day (1971).

Galluscio (1971), however, did not find an ECS perseveration effect, using a free operant procedure and 1,000 training trials. He found that CRF-trained Ss given ECS did not make significantly more responses in extinction than did CRF-trained Ss given no treatment. The present study was designed to determine: (1) whether or not an ECS perseveration effect can be obtained using a free operant procedure, and (1) if so, the effect of varying the amount of training on this ECS perseveration effect.

\section{METHOD \\ Subjects}

The Ss were 48 naive female albino rats, $175-200 \mathrm{~g}$ in weight at the start of the experiment.

\section{Apparatus}

The apparatus consisted of two identical Scientific Prototype operant chambers, each enclosed in a sound-insulated ventilated cubicle. Each operant chamber had a grid floor, and fitted on the end wall was a retractable lever and a liquid dipper that dispensed $.01 \mathrm{ml}$ of a $40 \%$ sucrose solution used as a reinforcement. All E-controlled events were operated by an electronic programming device. 
Table 1

Mean Number of Leverpresses in Extinction

\begin{tabular}{|c|c|c|c|c|c|}
\hline Group & $\begin{array}{c}\text { First } \\
\text { Minute }\end{array}$ & Total & Group & $\begin{array}{c}\text { First } \\
\text { Minute }\end{array}$ & Total \\
\hline $100(00)$ & 7.00 & 36.13 & 100 (ECS) & 9.75 & 52.38 \\
\hline $300(00)$ & 15.13 & 51.75 & 300 (ECS) & 13.00 & 62.38 \\
\hline $500(00)$ & 18.63 & 63.50 & 500 (ECS) & 18.13 & 66.00 \\
\hline
\end{tabular}

\section{Procedure}

The Ss were selected randomly from the LSU colony. They were placed in individual cages and on a food-deprivation schedule consisting of $10 \mathrm{~g}$ of Purina Chow every $24 \mathrm{~h}$. Water was available in the cages at all times, and $S s$ were fed approximately $10 \mathrm{~min}$ after each experimental session. From Day 1 to Day 4, Ss adapted to the deprivation schedule.

From Day 5 to Day 8, Ss were handled in pairs for $5 \mathrm{~min}$ daily, and on the 9 th day began magazine training on a VI 30 -sec schedule. Experimental periods consisted of 20 presentations of the dipper and were continued for 4 days. On the 13 th day, all Ss were conditioned to leverpress and, on the following day, were allowed to make 100 reinforced responses. On the 15 th day, Ss were divided randomly into three groups, 100-trial, 300-trial, and 500-trial, and began acquisition training. For the 100-trial group, Ss were given a total of 100 leverpresses; for the 300-trial group, Ss were given a total of 300 leverpresses; and for the 500-trial group, Ss were given a total of 500 leverpresses. Acquisition was under a CRF schedule for all Ss. All Ss were given 100 leverpresses daily, using a free operant procedure.

Following the completion of acquisition, each group was subdivided randomly, resulting in the following six groups $(\mathrm{N}=8)$ :

Groups 100(ECS), 300(ECS), and 500(ECS)-For Ss in these three groups, immediately following completion of acquisition, microalligator clips connected to an ECS source were attached to S's ears. A 50-mA 500-msec ECS was delivered through the earclip electrodes.

Groups $100(00), 300(00)$, and $500(00)-$ For Ss in these three groups, treatment was identical to the three groups above except that no ECS was delivered.

On the day following treatment, Ss were subjected to a 10-min extinction session. During extinction, the stimulus conditions were the same as during acquisition except that the dipper was inoperative.

\section{RESULTS}

The total number of responses made by each $\mathrm{S}$ in extinction was recorded at the end of the first minute and at the end of the 10-min period. The results of the first minute showed that more responses were made by Group 500(00), followed in order by Groups 500(ECS), 300(00), 300(ECS), 100(ECS), and 100(00). These data were subjected to an analysis of variance which showed

Table 2

Mean Number of Responses Per Minute

\begin{tabular}{cccccc}
\hline Group & $\begin{array}{c}\text { Acqui- } \\
\text { sition }\end{array}$ & Testing & Group & $\begin{array}{c}\text { Acqui- } \\
\text { sition }\end{array}$ & Testing \\
\hline $100(00)$ & 13.70 & 3.16 & 100 (ECS) & 11.34 & 5.24 \\
$300(00)$ & 15.13 & 5.18 & 300 (ECS) & 16.34 & 6.24 \\
$500(00)$ & 16.05 & 6.35 & 500 (ECS) & 18.35 & 6.60 \\
\hline
\end{tabular}

that only the training effect was significant $(p<.01)$. A priori group comparisons (t tests) showed that $100(00)$ vs $300(00), 100(00)$ vs $500(00)$, and $100(E C S)$ vs 500 (ECS) were significant beyond the .01 level. The comparisons $100(00)$ vs $100(E C S), \quad 300(00)$ vs 300 (ECS), $500(00)$ vs $500(\mathrm{ECS}), 300(00)$ vs $500(00)$, 100 (ECS) vs 300 (ECS), and 300 (ECS) vs 500 (ECS) were not significant at the .05 level.

The results of the 10-min period showed that more responses were made by Group 500(ECS), followed in order by Groups 500(00), 300(ECS), 300(00), 100(ECS), and 100(00). These data were subjected to an analysis of variance which showed that the training main effect was significant $(p<.05)$. A priori group comparisons ( $t$ tests) showed that $100(00)$ vs $100(E C S)$, $100(00)$ vs $300(00)$, and $100(00)$ vs $500(00)$ were significant beyond the .05 level. The comparisons $300(00)$ vs $300(\mathrm{ECS}), 500(00)$ vs $500(\mathrm{ECS}), 300(00)$ vs $500(00), 100(\mathrm{ECS})$ vs 300(ECS), 100(ECS) vs 500(ECS), and 300(ECS) vs 500(ECS) were not significant at the .05 level. The mean number of responses for all groups is shown in Table 1.

Table 2 shows group mean response rates for the last day of acquisition and during the extinction session. Although there was no difference in acquisition response rates for the 00 and ECS groups, Ss given 100 training trials were significantly slower than Ss given 500 training trials $(p<.05$, Mann-Whitney U). A comparison of response rates for the extinction session showed Group 100(00) to be significantly slower than Group 100(ECS)) $(p<.05)$, and Group 100(00) to be significantly slower than Group 500(00) $(p<.05)$ (both Mann-Whitney U tests).

\section{DISCUSSION}

A critical finding of this study is that, following 100 training trials, Ss given ECS responded significantly more in extinction than did Ss given no treatment. This finding indicates that an ECS perseveration effect can be obtained using a free operant procedure. This is in agreement with Keyes (1971), in which a perseveration effect was obtained using a discrete trial procedure.

The failure of the 300(ECS) group to respond significantly more than the $300(00)$ group and the failure of the 500(ECS) group to respond significantly more than the 500(00) group are also critical findings of the present study. These two findings extend the findings of the Galluscio (1971) study, in which 1,000 trials were given and no differences between the ECS and the no-treatment groups were found.

The combined findings suggest that with a free operant procedure, it is only with a very limited number of training trials that a perseveration effect is obtained, while with a discrete trial procedure a much greater number of leverpresses can be used.

The finding that the $300(00)$ group responded significantly more in extinction than did the 100(00) 
group and that the $500(00)$ group responded significantly more than the $100(00)$ group indicates differential resistance to extinction resulting from level of training. Following the administration of ECS, there was no significant difference in the number of responses in extinction for these various levels of training. These findings are similar to the failure of partial reinforcement-trained Ss to show the partial reinforcement effect (PRE) in extinction following the administration of shock followed by ECS (Young \& Galluscio, 1970; Young \& Day, 1971) or following the administration of ECS alone (Keyes, 1971).

The fact that ECS produces a loss of the PRE and also a similar loss in the differential resistance to extinction produced by varying the level of training suggests a single underlying process. The ECS perseveration effect is not peculiar to any particular schedule of reinforcement or to any particular level of training in itself, but rather, these results suggest that the perseveration effect depends on the resistance to extinction prior to the administration of ECS.

\section{REFERENCES}

Galluscio, E. H. Retrograde amnesia induced by electroconvulsive shock and carbon dioxide anesthesia in rats: An attempt to stimulate recovery. Journal of Comparative \& Physiological Psychology, 1971, 75, 136-140.

Keyes, J. B. The perseverating effect of ECS on a learned response following continuous and partial reinforcement training. Unpublished master's thesis, Louisiana State University, 1971.

Lewis, D. J. Sources of experimental amnesia. Psychological Review, 1969, 76, 461-472.

McGaugh, J. L. Time-dependent processes in memory storage. Science, 1966, 153, 1351-1358.

Young, A. G., \& Day, H. D. Effect of ECS on one-trial learning and on the partial reinforcement effect. Psychonomic Science, 1971, 24, 99-100.

Young, A. G., \& Galluscio, E. H. Effect of ECS on one-trial learning following continuous and partial reinforcement training. Psychonomic Science, 1970, 21, 43-44.

(Received for publication August 28, 1972; accepted October 24,1972 .) 